\title{
Tumor suppression, dose-limiting toxicity and wellbeing with the fetal estrogen estetrol in patients with advanced breast cancer
}

\author{
Marcus Schmidt ${ }^{1}$ Hans Lenhard ${ }^{2} \cdot$ Arnd Hoenig $^{2} \cdot$ Yvette Zimmerman $^{3} \cdot$ Jan $\mathrm{Krijgh}^{3} \cdot$ Monique Jansen $^{3}$. \\ Herjan J. T. Coelingh Bennink ${ }^{3}$ (i)
}

Received: 29 September 2020 / Accepted: 13 November 2020 / Published online: 26 November 2020

(c) The Author(s) 2020

\begin{abstract}
Purpose The aim of this study (the ABCE4 study) was to assess dose-limiting toxicity (DLT), safety, tolerability and preliminary efficacy of high doses of the fetal estrogen estetrol (E4) in postmenopausal patients with heavily pretreated, locally advanced and/or metastatic ER+/HER2-breast cancer, resistant to anti-estrogens.

Methods This was a multicenter, open-label, phase IB/IIA, dose-escalation study with a $3+3$ cohort design, whereby successive cohorts of three patients received $20 \mathrm{mg}, 40 \mathrm{mg}$ or $60 \mathrm{mg}$ E4 per day for 12 weeks by oral administration. DLTs, safety and wellbeing were evaluated after 4,8 and 12 weeks of treatment. Anti-tumor effects were investigated by computer tomography scanning and evaluated according to RECIST criteria before and after 12 weeks of treatment. Wellbeing was judged weekly by the investigator and by quality-of-life questionnaires by the patients. In view of the small number of patients, no statistical testing was performed.

Results All 12 patients enrolled had progressive, heavily pre-treated advanced breast cancer. No treatment-related serious adverse events or DLTs occurred during the first 4 weeks of E4 treatment allowing the investigation of all three doses. Five of nine patients completing 12 weeks of E4 treatment showed objective anti-tumor effects and six of nine patients reported improved wellbeing.

Conclusion High doses of estetrol seem to be safe and are well tolerated during 12 weeks of treatment without dose-limiting toxicity and with anti-tumor effects in five of nine heavily treated patients with progressive, anti-estrogen resistant, advanced breast cancer.
\end{abstract}

Keywords Advanced breast cancer · Estetrol (E4) · High-dose estrogen (HDE) treatment

\section{Introduction}

Breast cancer is the most commonly diagnosed cancer and the leading cause of cancer death in women (Bray et al. 2018), with metastatic disease accounting for the majority of deaths (Dillekas et al. 2019). In most women treated with anti-estrogens, the mainstay of initial treatment, recurrence due to the development of drug resistance occurs,

Herjan J. T. Coelingh Bennink

hcb@pantarheibio.com

1 Department of Obstetrics and Gynecology, University Medical Center Mainz, 55122 Mainz, Germany

2 Department of Obstetrics and Gynecology, Katholisches Klinikum Mainz, 55131 Mainz, Germany

3 Pantarhei Oncology BV, Boulevard 17, 3707 BK Zeist, The Netherlands especially in the metastatic setting (D'Souza et al. 2018; Haque and Desai 2019; Szostakowska et al. 2019). Resistance to endocrine therapy is a major challenge, prompting the need for new treatment options (D'Souza et al. 2018; Haque and Desai 2019; Szostakowska et al. 2019). In particular, there is a need for efficacious treatments that can improve or maintain patients' quality of life (QoL) (Cardoso et al. 2014; Janni et al. 2019).

High doses of estrogens (HDE), such as ethinylestradiol (EE), estradiol (E2) and diethylstilbestrol (DES), are effective for the treatment of breast cancer, especially in postmenopausal women, who are at least 5 years after menopause and/or in women who are resistant to anti-estrogens (Coelingh Bennink et al. 2017a). Due to side effects, especially thrombosis and other cardiovascular complications, HDE treatment has been replaced by anti-estrogens, such as tamoxifen, aromatase inhibitors (AIs) and fulvestrant 
(Croxtall and McKeage 2011; Ingle et al. 1981; Reinert and Barrios 2017). However, due to their strong anti-estrogenicity, these compounds induce serious unwanted signs and symptoms of estrogen deficiency, interfering with QoL and especially with long-term drug compliance (Ciruelos et al. 2014; Kwan et al. 2017; Makubate et al. 2013). Recently, CDK4/6 inhibitors have obtained an important position in the treatment of advanced breast cancer after failure of antiestrogens, but these compounds also have side effects and interfere with QoL (Howie et al. 2019; Lasheen et al. 2017; Messina et al. 2018).

The fetal estrogen estetrol (E4) is a potential new HDE treatment for anti-estrogen-resistant ER+/HER- advanced breast cancer. The term "estetrol" refers to estra-1,3,5(10)triene-3,15 $\alpha, 16 \alpha, 17 \beta$-tetrol, an estrogenic steroid, produced under physiological conditions only during human pregnancy by the fetoplacental unit (Hagen et al. 1965). It is also known as E4, referring to the four OH groups in the molecule at positions 3, 15, 16 and 17 (Fig. 1). Estetrol was first identified by Egon Diczfalusy et al. in 1965 at the Karolinska Institute in Stockholm, Sweden (Hagen et al. 1965) and was discovered as a potential estrogenic drug for human use in 2001 by the last author of this paper at Pantarhei Bioscience in the Netherlands (Hagen et al. 1965; Holinka et al. 2008). Extensive (human) pharmacological and safety and dosefinding studies have been performed for the development of $\mathrm{E} 4$ as the estrogen in a combined oral contraceptive (COC) and for menopausal hormone therapy (MHT) (Apter et al. 2016; Coelingh Bennink et al. 2008b, 2016, 2017b, c; Duijkers et al. 2015; Gaspard et al. 2020; Holinka et al. 2008). These studies have demonstrated a more favorable cardiovascular risk profile of $\mathrm{E} 4$ compared to other natural and synthetic estrogens used for these applications in the past (Apter et al. 2016; Coelingh Bennink et al. 2016). For both the COC and the MHT application, a daily dose of $15 \mathrm{mg}$ $\mathrm{E} 4$ has been selected and studied in randomized controlled studies (Apter et al. 2016; Gaspard et al. 2020).

There are several reasons why E4 in particular can be used for a HDE in cancer treatment. First, E4 has a long oral elimination half-life (Visser et al. 2008), which makes it suitable for use as a once-a-day oral drug. Second, it is a metabolic end product, without active and potentially toxic metabolites (Coelingh Bennink et al. 2008a). Third, compared to other estrogens, E4 shows little interaction with liver function and steroid- and drug-metabolizing liver enzymes (Mawet et al. 2015). In particular, the limited interference of $\mathrm{E} 4$ with liver factors involved in hemostasis provides hope for a lower risk of cardiovascular (CV) side effects (Douxfils et al. 2020; Kluft et al. 2017), which was the major reason for discarding estrogens for the treatment of breast cancer in the past. Fourth, in preclinical breast cancer studies, in in vitro models, E4 antagonized the proliferative effect on tumor growth of E2 in MCF-7 and LTED cells (Giretti et al. 2014). Fifth, in the in vivo rat DMBA model, high-dose E4 completely prevented breast tumor development comparable to ovariectomy, whereas in the therapeutic DMBA model, E4 inhibited the further growth of existing mammary tumors (Visser et al. 2012). Last but not least, high-dose E4 (HDE4) tumor treatment is expected to improve patients' wellbeing and QoL by decreasing signs and symptoms of estrogen deficiency due to postmenopausal or anti-estrogenic estrogen depletion.

The first study with E4 in women with breast cancer was performed by Singer et al. in 30 women with recently
Fig. 1 The four natural estrogens
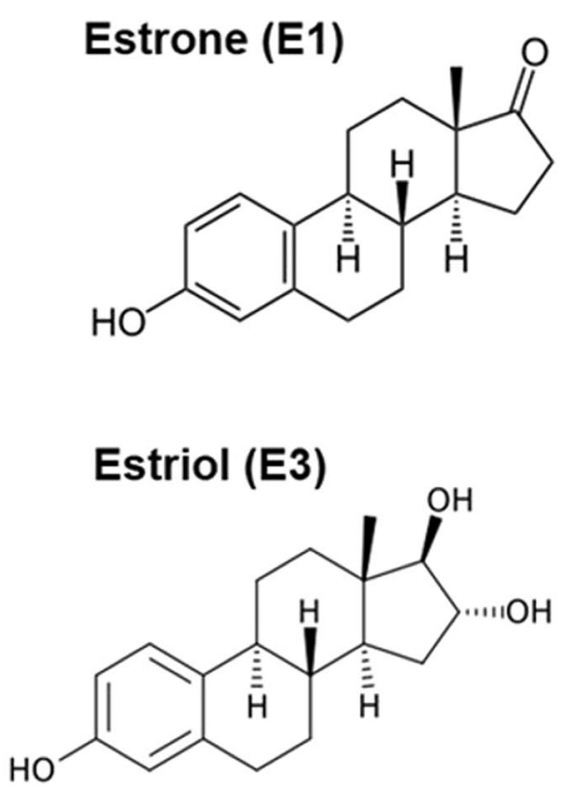

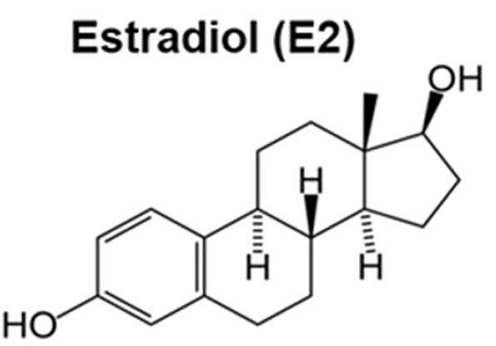<smiles>C[C@]12CC[C@H]3c4ccc(O)cc4CC[C@H]3[C@@H]1[C@@H](O)[C@H](O)[C@H]2O</smiles> 
diagnosed ER+ breast cancer, who were treated in a prospective, randomized, double-blind, placebo-controlled, neo-adjuvant study for 2 weeks with $20 \mathrm{mg}$ E4 per day or placebo. The most relevant results of this study were that E4 significantly induced apoptosis and increased the expression of the anti-proliferative ERbeta receptor in the breast tumors (Singer et al. 2014).

Altogether, the data suggest that: (1) E4 may be safer for the CV system than other estrogens, (2) HDE4 may be an effective anti-tumor treatment and (3) HDE4 may maintain or improve QoL.

Here, we report the results of the "Advanced Breast Cancer Estetrol" (ABCE4) study, a phase IB/IIA, dose-escalation study with E4 in postmenopausal women with progressive ER+/HER2- end-stage breast cancer with resistance or intolerance to tamoxifen or AIs without established therapeutic alternatives, including chemotherapy. The primary objective of this study was to assess the dose-limiting toxicity (DLT) and to estimate the maximum recommended and optimal dose of E4. The secondary objectives included the assessment of the safety and tolerability of E4, the subjective clinical evaluation of QoL related to estrogen-deficiency symptoms, and a preliminary assessment of the efficacy of HDE4 in terms of anti-tumor response.

\section{Methods}

\section{Study design and patients}

The ABCE4 study was an open-label, phase IB/IIA, doseescalation study performed in two centers in Germany (ClinicalTrials.gov identifier: NCT02718144; Eudra-CT number 2016-003707-57). It consisted of a $3+3$ cohort design, whereby successive cohorts of three patients received $20 \mathrm{mg}$, $40 \mathrm{mg}$, or $60 \mathrm{mg} \mathrm{E} 4$ per day by oral administration.

Key inclusion criteria included: a natural or surgical menopause at least 5 years previously; progressive ER+ and HER2 - locally advanced and/or metastatic breast cancer without established therapeutic alternatives; failure of antiestrogen treatment with tamoxifen and/or $\mathrm{AI}(\mathrm{s})$ due to the development of resistance or unacceptable side effects; a life expectancy of at least 6 months and a body mass index (BMI) between 18 and $35 \mathrm{~kg} / \mathrm{m}^{2}$. Patients with a history of venous or arterial thromboembolic disease or a known defect in the blood coagulation system were excluded. In addition, patients who had been treated with fulvestrant within 6 months prior to the start of E4 treatment were excluded, since this treatment destroys the ER, which is essential for allowing E4 receptor-mediated efficacy. As of the second cohort, patients with a history of severe cardiac events or life-threatening cardiac dysrhythmia, unstable angina or clinical congestive heart failure were excluded and patients had to have an Eastern Cooperative Oncology Group (ECOG) performance status of 0-2.

\section{Ethics}

The study was conducted according to Good Clinical Practice (GCP) and in accordance with the Declaration of Helsinki and International Council for Harmonization of Technical Requirements for Pharmaceuticals for Human Use. The study was approved by the independent ethics committee Landesärztekammer Rheinland-Pfalz (Germany). Each patient provided written informed consent prior to screening. An independent data monitoring committee was in place to oversee the study, to evaluate safety and to decide on dose escalation.

\section{Study medication}

Patients were treated for 12 weeks with E4; the first 4 weeks in a phase IB safety setting and thereafter 8 weeks in phase IIA to extend the safety observations and allow for a preliminary efficacy evaluation. Phase IB of the study followed the traditional $3+3$ study design to determine the optimal dose of E4. Patients were treated in cohorts of 3 receiving the same dose. Occurrence of DLTs at completion of phase IB after 4 weeks treatment determined escalation to the next higher dose. After completion of the $20 \mathrm{mg}$ and the $40 \mathrm{mg}$ E4 dose cohort, safety and tolerance data were evaluated before proceeding to the next higher dose.

After completion of phase IB, patients continued treatment for 8 weeks at their individual phase IB dose level to assess the safety and preliminary anti-tumor response in phase IIA. Thereafter, further extension of treatment was possible beyond 12 weeks.

The study medication was supplied in tablets of $20 \mathrm{mg}$ for oral administration and packed in blisters by Haupt Pharma, Münster, Germany. All tablets (1, 2 or 3 ) were to be taken once daily in the morning.

\section{Study procedures}

Patients were screened before the start of study medication. Study visits were scheduled on Days 1, 8, 15, 28, 56, and 84 . In addition, patients were contacted by telephone on Days 42 and 70 for an additional check of wellbeing. Safety, tolerance and toxicity assessments included the recording of adverse events (AEs) using Common Terminology Criteria for Adverse Events, version 4.03 (CTCAE v4.03), physical examination, vital signs (blood pressure and heart rate), body weight, electrocardiograms and safety laboratory parameters (hematology and biochemistry). Treatmentemergent adverse events (TEAEs) were defined as those AEs 
occurring from the time of first study medication intake until the last visit.

Objective anti-tumor effects were assessed by CT scanning and evaluated according to the RECIST criteria (version 1.1) before and after 12 weeks of treatment and thereafter every 12 weeks in case of extended treatment. External independent verification of the CT scans was performed by Prof Adrian Lim, Clinical Radiologist, Imperial College, London, UK. Wellbeing (QoL) was assessed by means of specific questions about estrogen-deficiency symptoms, derived from the validated Functional Assessment of Cancer Therapy Endocrine Subscale (FACT-ES) (Fallowfield et al. 1999). A safety review committee (SRC) including the investigators and sponsor representatives had weekly meetings to evaluate the safety and tolerability of E4 continuously and to assess wellbeing of the patients based on the clinical judgement of the treating oncologists [MS and AH]. At the end of the treatment, patients completed a treatment satisfaction questionnaire.

\section{Statistical analysis}

This was a dose-escalation study, with no formal hypothesis testing, and hence no sample size calculation was performed. In view of the small numbers of study participants required for this standard $3+3$ design study, no statistical test procedures have been performed and individual results are presented without means and standard deviations or medians and ranges.

All subjects who received treatment were included in the evaluation of the safety data. The per-protocol population, defined as the subjects who completed the study without major protocol deviations, was used for the evaluation of efficacy.

\section{Results}

\section{Patients}

A total of 12 postmenopausal women with heavily pretreated breast cancer were enrolled in the ABCE4 study, of whom 11 received treatment (Fig. 2). One patient withdrew informed consent prior to starting treatment. Nine patients completed phase IB. Two patients withdrew in phase IB due to the severity of their disease (disease progression and noncompliance due to the severity of disease).

Eight patients completed both the phase IB and IIA part of the study. One patient in the $20 \mathrm{mg}$ group discontinued the study during phase IIA due to disease progression after 9.5 weeks of E4 treatment. She died 2 weeks later.

Six patients requested continuation of E4 treatment beyond the trial period of 12 weeks, with the other two patients stopping at the end of phase IIB period due to disease progression. Overall, there were no discontinuations due to drug-related adverse events during the phase IA/IIB period.

At the data cut-off date for this paper (November 2020), one patient was still continuing treatment with $20 \mathrm{mg}$ E4 (35 months of treatment). During these almost three years of treatment with $20 \mathrm{mg}$ E4 with stable BC disease, this patient experienced three episodes of vaginal bleeding after
Fig. 2 Patient disposition (CONSORT diagram)

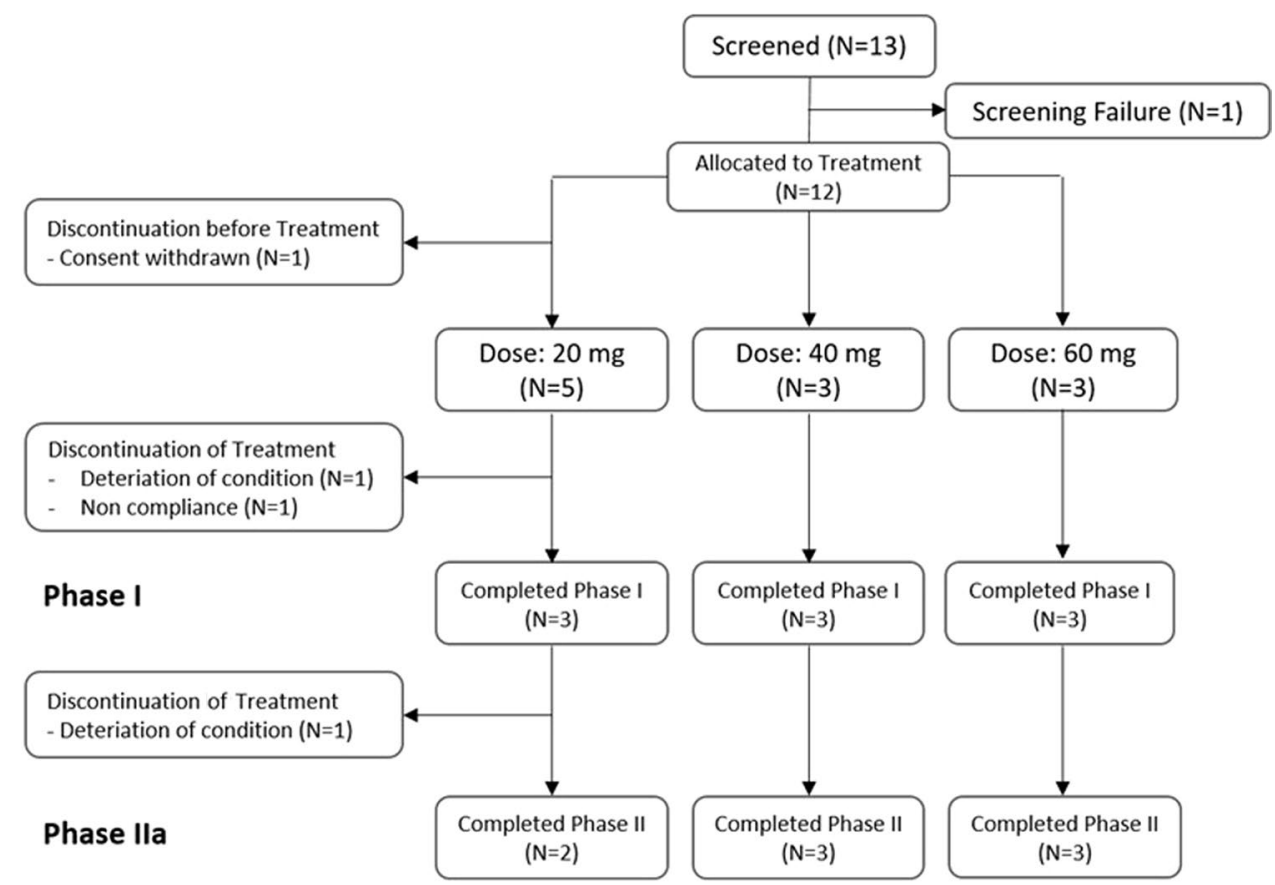


7, 9 and 19 months and of 1,9 and 1 day duration, respectively. A D\&C was performed during the second and third events. No endometrial abnormalities were found. The other five patients requesting follow-up E4 treatment discontinued after 13-48 weeks of treatment due to progression of the BC disease. In two patients taking 20 and $40 \mathrm{mg} \mathrm{E} 4$, a short and mild episode of vaginal bleeding was reported after 5 and 4 months treatment, respectively, not requiring intervention and with spontaneous recovery.

\section{Baseline characteristics}

Table 1 provides the baseline patient characteristics, the details concerning the breast cancer status and the medical and treatment history of the 11 patients treated. All had experienced a spontaneous or medically induced menopause more than 5 years ago and had been treated with anti-estrogenic drugs until resistance occurred. All patients had been treated with multiple endocrine, targeted and chemotherapies except one patient (no. 2), who had refused further targeted or chemotherapy after resistance to endocrine therapy had occurred. This is the patient still on $20 \mathrm{mg}$ E4 treatment at the time of writing this manuscript.

\section{Dose-limiting toxicity, safety and tolerability}

None of the patients experienced a DLT. All three E4 doses were well tolerated by all 11 patients treated. In total, 31 TEAEs were reported by 8 patients, mainly of mild or moderate intensity (Table 2). Six events were considered possibly related to E4 treatment: dry skin, pruritis and endometrial hyperplasia in one patient using $20 \mathrm{mg} \mathrm{E} 4$, fatigue and 4 days vaginal bleeding resolving spontaneously in a second patient on $20 \mathrm{mg} \mathrm{E} 4$ and regurgitation in a third patient on $40 \mathrm{mg}$ E4. No drug-related serious AEs were reported.

\section{Anti-tumor activity}

After 12 weeks of E4 treatment, five of nine patients showed objective anti-tumor effects with stable disease in four patients and one complete response, judged according to RECIST criteria (Table 3). The percentage change of tumor diameters from baseline per patient in eight patients is shown in Fig. 3. Both the complete response as well as the highest increase of tumor diameter occurred with the $20 \mathrm{mg}$ E4 dose. The third patient in the $20 \mathrm{mg}$ group and all 3 patients treated with $40 \mathrm{mg}$ E4 showed stable disease. All three patients treated with the highest E4 dose of $60 \mathrm{mg}$ demonstrated progressive tumor growth. The five patients demonstrating an anti-tumor effect requested continuation of E4 treatment beyond the trial. Tumor assessment after 24 weeks of treatment confirmed stable disease in four of four patients investigated.

\section{Quality of life}

Overall, the total QoL scores for estrogen-deficiency symptoms in the nine treated patients were maintained at high levels from baseline to the end of the phase IIb period (range 65-75 at baseline to $61.5-76$ at end of treatment; Fig. 4). Based on investigator's reporting during the SRC meetings, six of nine patients mentioned verbally to the investigators that they felt very well. Four patients reported to be very satisfied with the medication and these patients also said they would consider taking the medication in the future, whereas one patient was very dissatisfied with the result of treatment.

\section{Discussion}

The results of this first study with high daily doses of 20, 40 or $60 \mathrm{mg}$ of the fetal estrogen estetrol (E4) in nine patients with progressive locally advanced and/or metastatic breast cancer showed no DLTs or serious adverse events related to E4 during 12 weeks of treatment and was well tolerated by all patients. High daily doses of 20 or $40 \mathrm{mg}$ E4 demonstrated a significant anti-tumor effect in five of nine patients after 12 weeks of $\mathrm{E} 4$ treatment with disappearance of some tumors and no further growth of other tumors. According to the RECIST criteria, the effect of HDE4 was classified as stable disease in four cases and a complete response in one case. These results are consistent with earlier in vivo observations in the DMBA rat model mentioned in the introduction of this paper (Visser et al. 2012).

From the 1940 s to the 1960 s, HDE treatment was routinely used for the endocrine treatment of advanced breast cancer and was later replaced by tamoxifen, AIs and fulvestrant (Coelingh Bennink et al. 2017a). In recent years, antiendocrine treatment has been combined with novel chemotherapeutics, such as CDK4/6 inhibitors, mTOR antagonists and PI3K-inhibitors, to overcome endocrine resistance and to delay progression of disease. All these compounds also cause side effects in addition to the known side effects of anti-estrogenic therapy.

Evidence suggests that HDE is especially effective in women with ER+ breast cancer, who are at least 5 years after menopause and/or in women who have become resistant to anti-estrogens (Coelingh Bennink et al. 2017a). The mechanism of action of HDE under these conditions has been studied extensively by the groups of Santen (Song et al. 2001) and Jordan (Jordan 2015), concluding that apoptosis was observed in responding breast tumors. This is confirmed by the first ever study with HDE4 by Singer et al. (2014), mentioned in the introduction of this paper. The molecular mechanism of action of this estrogen-induced apoptosis requires further investigation. 


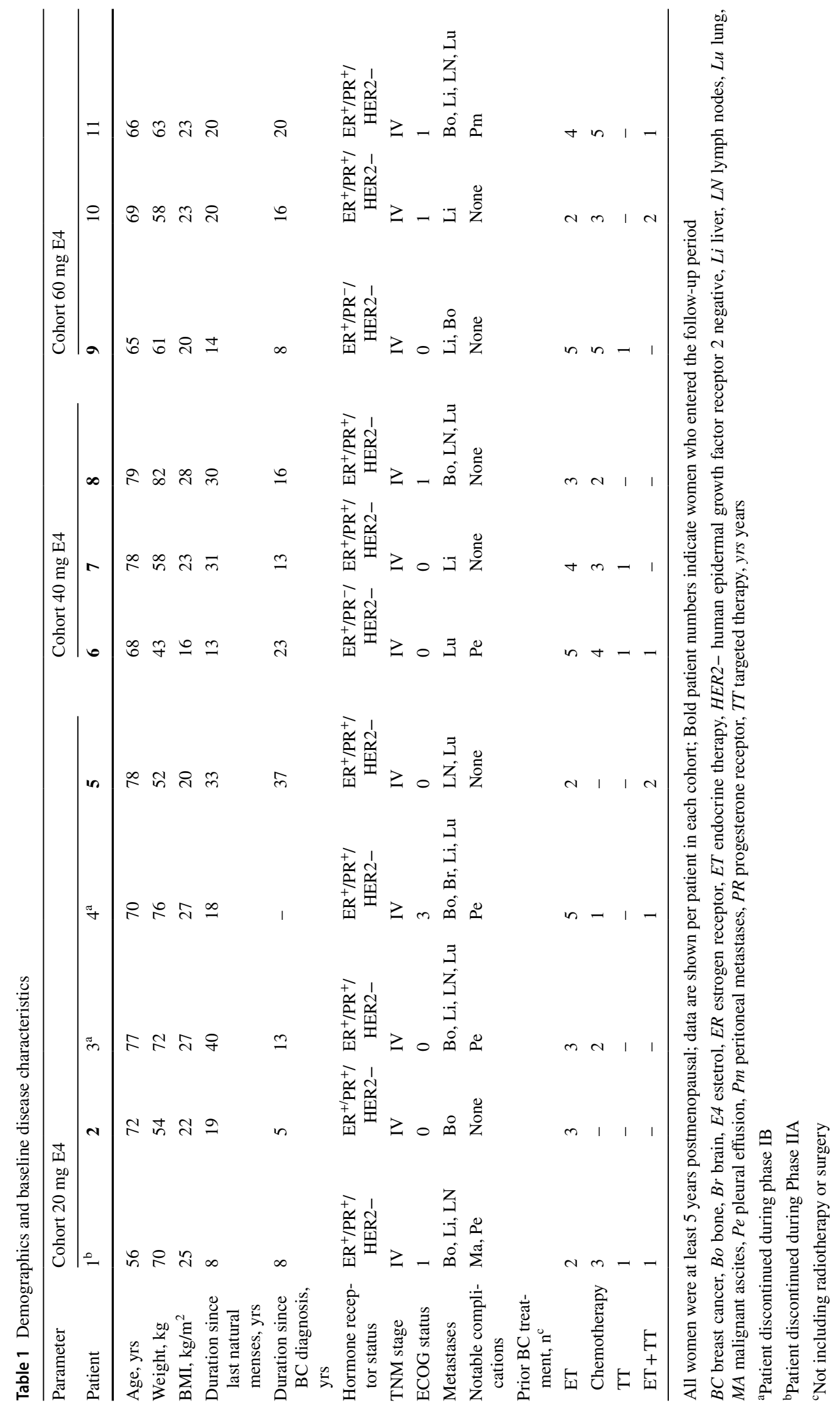


Table 2 Number of patients reporting adverse events

\begin{tabular}{lllll}
\hline Adverse events, $n(\%)$ & $\begin{array}{l}20 \mathrm{mg} \text { cohort } \\
(N=5)\end{array}$ & $\begin{array}{l}40 \mathrm{mg} \text { cohort } \\
(N=3)\end{array}$ & $\begin{array}{l}60 \mathrm{mg} \text { cohort } \\
(N=3)\end{array}$ & Total $(N=11)$ \\
\hline TEAEs & $5(100)$ & $1(33.3)$ & $2(66.7)$ & $8(72.7)$ \\
Drug-related TEAEs & $2(40)$ & $1(33.3)$ & 0 & $3(27.3)$ \\
Grade 3 or 4 TEAEs & $1(20)$ & 0 & $1(33.3)$ & $2(18.2)$ \\
SAEs & $3(60)$ & 0 & $1(33.3)$ & $4(36.4)$ \\
$\begin{array}{l}\text { Drug-related SAEs } \\
\text { TEAEs resulting in study drug } \\
\text { discontinuation }\end{array}$ & 0 & 0 & 0 & 0 \\
\hline
\end{tabular}

TEAEs treatment-emergent adverse events, SAEs serious adverse events

\begin{tabular}{|c|c|c|c|c|c|c|c|c|c|}
\hline \multirow{2}{*}{$\begin{array}{l}\text { Evaluation } \\
\text { Patients }\end{array}$} & \multicolumn{3}{|c|}{$20 \mathrm{mg} \mathrm{E} 4$} & \multicolumn{3}{|c|}{40 mg E4 } & \multicolumn{3}{|c|}{$60 \mathrm{mg} \mathrm{E} 4$} \\
\hline & 1 & 2 & 5 & 6 & 7 & 8 & 9 & 10 & 11 \\
\hline Evaluation of target lesions & PD & SD & $\mathrm{CR}$ & SD & SD & SD & PD & PD & PD \\
\hline Evaluation of non-target lesions & PD & $\begin{array}{c}\text { Non- } \\
\text { CR/ } \\
\text { non- } \\
\text { PD }\end{array}$ & $\begin{array}{c}\text { Non- } \\
\text { CR/ } \\
\text { non- } \\
\text { PD }\end{array}$ & $\begin{array}{c}\text { Non- } \\
\text { CR/ } \\
\text { non- } \\
\text { PD }\end{array}$ & $\begin{array}{c}\text { Non- } \\
\text { CR/ } \\
\text { non- } \\
\text { PD }\end{array}$ & $\begin{array}{c}\text { Non- } \\
\text { CR/ } \\
\text { non- } \\
\text { PD }\end{array}$ & PD & - & PD \\
\hline New lesions & Yes & No & No & No & No & No & Yes & Yes & No \\
\hline Response type & PD & SD & $\mathrm{CR}$ & SD & SD & SD & PD & PD & PD \\
\hline Response & No & Yes & Yes & Yes & Yes & Yes & No & No & No \\
\hline
\end{tabular}

$E 4$ estetrol, $C R$ complete response, $S D$ stable disease, $P D$ progressive disease

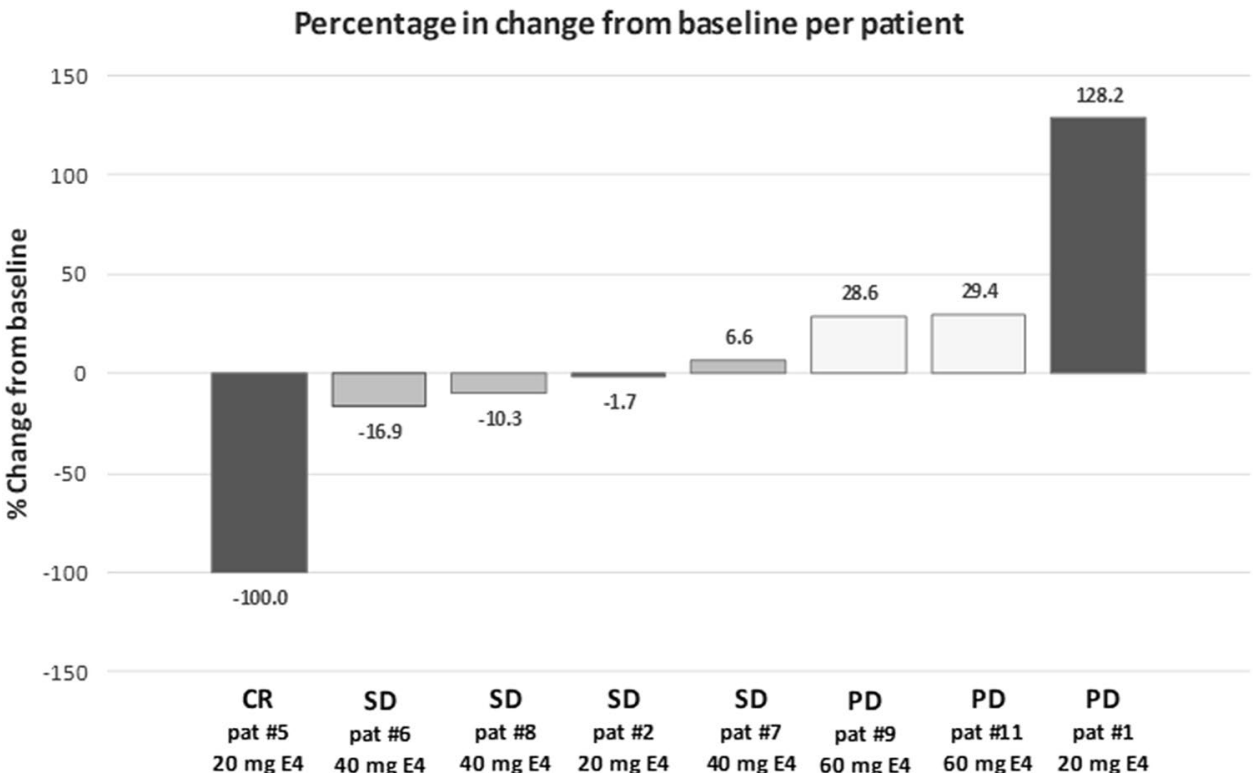

Fig. 3 Percentage change of tumor diameters from baseline per patient
Table 3 Anti-tumor response after 12 weeks of E4 treatment according to RECIST criteria
There is a place for a HDE treatment in patients with antiestrogen-resistant advanced breast cancer, provided such a treatment has a more favorable $\mathrm{CV}$ risk profile compared to the natural and synthetic estrogens used in the past. Preclinical and clinical studies with E4 support the potentially favorable CV safety profile of $\mathrm{E} 4$ in dosages up to $15 \mathrm{mg} \mathrm{E} 4$ per day for a year in contraceptive studies (Kluft et al. 2017; Mawet et al. 2015), and up to $40 \mathrm{mg}$ E4 per day for 28 days in MHT dose-finding studies (Coelingh Bennink et al. 2016).

Based on preclinical and clinical contraceptive and menopausal studies, the potency of E4 in the human is about $10 \times$ lower than that of E2 (Coelingh Bennink et al. 2016; 
Fig. 4 Total quality-of-life score

Total Score (range 0-76)

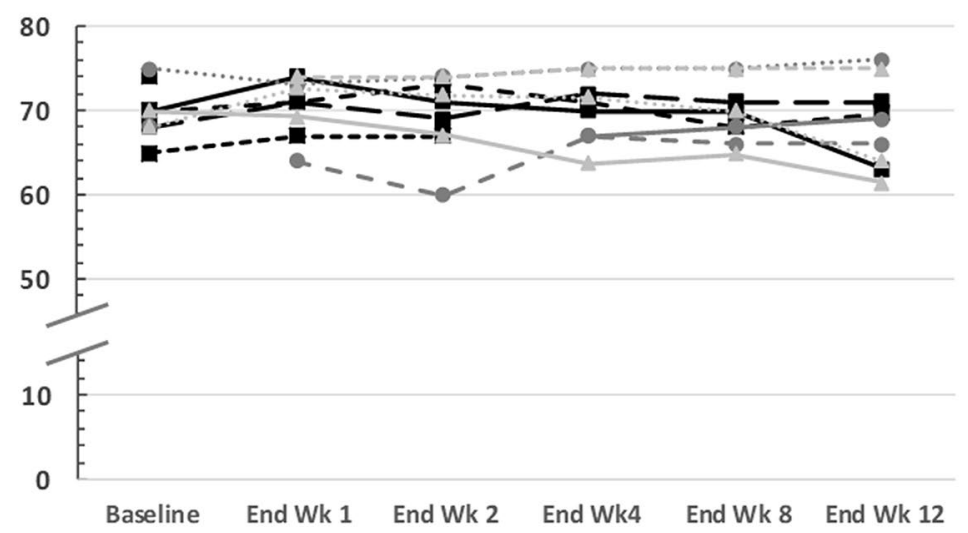

Maximum (good) quality of life score $=76$

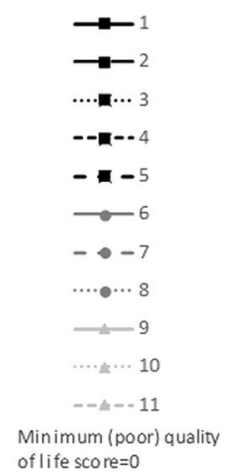

Duijkers et al. 2015), so the dose of 20, 40 and $60 \mathrm{mg} \mathrm{E} 4$ used by the patients reported here, is comparable to 2, 4 and $6 \mathrm{mg}$ E2. Ellis et al. investigated the effect of high-dose $6 \mathrm{mg}$ and $30 \mathrm{mg}$ E2 in women with anti-estrogen-resistant advanced breast cancer (Ellis et al. 2009). They observed equal efficacy of the 6 and $30 \mathrm{mg} \mathrm{E} 2$ doses, but the higher $30 \mathrm{mg}$ dose showed more serious side effects and drop-outs (Ellis et al. 2009). Based on these data and the observed potency ratio between $\mathrm{E} 2$ and $\mathrm{E} 4$ of a factor 10, the maximum E4 dose in the present E4 dose-escalation study was $60 \mathrm{mg}$.

We tested E4 in heavily pretreated late-stage patients with a life expectancy sufficiently long to enable judgement of the new treatment. Therefore, the anti-tumor effect in five of nine patients treated for 12 weeks, which was continued under compassionate use in five cases for 13-48 weeks, with one patient still on treatment to date (November 2020), is rather impressive, taking into consideration the seriousness of their disease.

These end-stage disease women with breast cancer are generally seriously estrogen deficient for very long periods, either by spontaneous or by induced menopause or more often due to long-term anti-estrogen treatments. This may cause not only annoying hot flushes and sweating interfering with sleep, but also osteoarthralgia (Fenton and Panay 2016). Furthermore, depression, and other mood changes, as well as more objective signs of estrogen deficiency, such as bone loss, fractures and cognition problems, occur. These signs and symptoms of estrogen deficiency are an important cause of non-compliance to and early discontinuation of anti-estrogen treatment. The use of HDE4 is expected to improve drug compliance and increase wellbeing, thereby creating a dual high-dose E4 efficacy of (1) an anti-tumor effect and (2) strong estrogen substitution. Short and spontaneously resolving vaginal bleeding suggesting some endometrial interaction occurred in the study once and during limited duration follow-up in two patients. The patient treated for almost 3 years now, with $20 \mathrm{mg}$ E4 per day experienced three episodes of vaginal bleeding with no signs of endometrial hyperplasia after D\&C. Nevertheless, HDE4 treatment of advanced BC in women with a uterus requires some type of endometrial control, although the results of this study are reassuring and suggest little effect of HDE4 on the endometrium. Rather surprisingly, the questionnaire for estrogen deficiency used in this study did not reveal estrogen-deficiency complaints at baseline. This may be due to the stage of the disease with low priority for not life-threatening complaints. According to the QoL questionnaire, quality of life was maintained by all nine patients treated. Six of nine patients reported improved wellbeing during treatment to the oncologist and after treatment four were very satisfied and another four were satisfied by the HDE4 treatment. Further clinical studies are needed to confirm the safety and the extent and duration of the anti-tumor effect of E4 in larger numbers of less seriously ill breast cancer patients and to document objectively the subjective effect of the strong estrogen substitution on QoL at an earlier stage of the disease.

\section{Conclusion}

High doses of estetrol seem to be safe and well tolerated during 12 weeks of treatment without dose-limiting toxicity and with anti-tumor effects in five of nine heavily pretreated patients with progressive, anti-estrogen resistant, advanced breast cancer.

Acknowledgements Carole Verhoeven (formerly at Pantarhei) is acknowledged for her participation in the set-up and organization of the study. Amanda Prowse (at Terminal 4 Communications, Hilversum, The Netherlands) is acknowledged for her contribution to the preparation of the manuscript.

Funding The study was organized and funded by Pantarhei Oncology BV, The Netherlands. 


\section{Compliance with ethical standards}

Conflict of interest MS received Grants and personal fees from PierreFabre and BioNTech; personal fees and non-financial support from Roche, Amgen and Pfizer; personal fees from Novartis, Astra-Zeneca, Celgene and Eisai, outside the submitted work. HL has nothing to disclose. AH obtained grants and personal fees from Roche and Genentech, personal fees and non-financial support from Roche, Amgen and Pfizer; personal fees from Novartis, Astra-Zeneca, PharMar and Celgene. JK is CMO of Pantarhei Oncology. MJ is an independent consultant and the project manager of the ABCE4 study. YZ is CEO of Pantarhei Bioscience and Pantarhei Oncology, and shareholder of Pantarhei Oncology. HCB is President and shareholder of Pantarhei Bioscience and Pantarhei Oncology.

Ethics approval All procedures performed in this study were in accordance with GCP, with the ethical standards of the institutional and/or national research committee and with the 1964 Helsinki Declaration and its later amendments or comparable ethical standards. The study was approved by the independent ethics committee Landesärztekammer Rheinland-Pfalz. Informed consent was obtained from all individual participants participating in the study.

Author contributions $\mathrm{MS} / \mathrm{HL} / \mathrm{AH}$ and $\mathrm{HCB}$ contributed to the concept and design of the study. MS/HL/AH recruited and treated the patients. All authors analyzed and interpreted the results and patient data and read and approved the final manuscript.

Open Access This article is licensed under a Creative Commons Attribution 4.0 International License, which permits use, sharing, adaptation, distribution and reproduction in any medium or format, as long as you give appropriate credit to the original author(s) and the source, provide a link to the Creative Commons licence, and indicate if changes were made. The images or other third party material in this article are included in the article's Creative Commons licence, unless indicated otherwise in a credit line to the material. If material is not included in the article's Creative Commons licence and your intended use is not permitted by statutory regulation or exceeds the permitted use, you will need to obtain permission directly from the copyright holder. To view a copy of this licence, visit http://creativecommons.org/licenses/by/4.0/.

\section{References}

Apter D, Zimmerman Y, Beekman L, Mawet M, Maillard C, Foidart JM, Bennink HJ (2016) Bleeding pattern and cycle control with estetrol-containing combined oral contraceptives: results from a phase II, randomised, dose-finding study (FIESTA). Contraception 94:366-373. https://doi.org/10.1016/j.contraception.2016.04.015

Bray F, Ferlay J, Soerjomataram I, Siegel RL, Torre LA, Jemal A (2018) Global cancer statistics 2018: GLOBOCAN estimates of incidence and mortality worldwide for 36 cancers in 185 countries. CA Cancer J Clin 68:394-424. https://doi.org/10.3322/ caac. 21492

Cardoso $\mathrm{F}$ et al (2014) ESO-ESMO 2nd international consensus guidelines for advanced breast cancer (ABC2). Breast 23:489-502. https://doi.org/10.1016/j.breast.2014.08.009

Ciruelos E et al (2014) The therapeutic role of fulvestrant in the management of patients with hormone receptor-positive breast cancer. Breast 23:201-208. https://doi.org/10.1016/j.breast.2014.01.016

Coelingh Bennink HJ, Heegaard AM, Visser M, Holinka CF, Christiansen C (2008a) Oral bioavailability and bone-sparing effects of estetrol in an osteoporosis model. Climacteric 11(Suppl 1):2-14. https://doi.org/10.1080/13697130701798692

Coelingh Bennink HJ, Skouby S, Bouchard P, Holinka CF (2008b) Ovulation inhibition by estetrol in an in vivo model. Contraception 77:186-190. https://doi.org/10.1016/j.contraception.2007.11.014

Coelingh Bennink HJT, Zimmerman Y, Verhoeven C, Visser M, Foidart JM, Gemzell-Danielsson K (2016) Clinical effects of the fetal estrogen estetrol in a multiple-rising-dose study in postmenopausal women. Maturitas 91:93-100

Coelingh Bennink HJT, Verhoeven C, Dutman AE, Thijssen J (2017a) The use of high-dose estrogens for the treatment of breast cancer. Maturitas 95:11-23

Coelingh Bennink HJT, Verhoeven C, Zimmerman Y, Visser M, Foidart JM, Gemzell-Danielsson K (2017b) Pharmacodynamic effects of the fetal estrogen estetrol in postmenopausal women: results from a multiple-rising-dose study. Menopause 24:677685. https://doi.org/10.1097/GME.0000000000000823

Coelingh Bennink HJT, Verhoeven C, Zimmerman Y, Visser M, Foidart JM, Gemzell-Danielsson K (2017c) Pharmacokinetics of the fetal estrogen estetrol in a multiple-rising-dose study in postmenopausal women. Climacteric 20:285-289

Croxtall JD, McKeage K (2011) Fulvestrant: a review of its use in the management of hormone receptor-positive metastatic breast cancer in postmenopausal women. Drugs 71:363-380. https:// doi.org/10.2165/11204810-000000000-00000

Dillekas H, Rogers MS, Straume O (2019) Are 90\% of deaths from cancer caused by metastases? Cancer Med 8:5574-5576. https ://doi.org/10.1002/cam4.2474

Douxfils J et al (2020) Evaluation of the effect of a new oral contraceptive containing estetrol and drospirenone on hemostasis parameters. Contraception. https://doi.org/10.1016/j.contracept ion.2020.08.015

D'Souza A, Spicer D, Lu J (2018) Overcoming endocrine resistance in metastatic hormone receptor-positive breast cancer. J Hematol Oncol 11:80. https://doi.org/10.1186/s13045-018-0620-6

Duijkers IJ et al (2015) Inhibition of ovulation by administration of estetrol in combination with drospirenone or levonorgestrel: results of a phase II dose-finding pilot study. Eur J Contracept Reprod Health Care 20:476-489. https://doi.org/10.3109/13625 187.2015.1074675

Ellis MJ et al (2009) Lower-dose vs high-dose oral estradiol therapy of hormone receptor-positive, aromatase inhibitor-resistant advanced breast cancer: a phase 2 randomized study. JAMA 302:774-780. https://doi.org/10.1001/jama.2009.1204

Fallowfield LJ, Leaity SK, Howell A, Benson S, Cella D (1999) Assessment of quality of life in women undergoing hormonal therapy for breast cancer: validation of an endocrine symptom subscale for the FACT-B. Breast Cancer Res Treat 55:189-199. https://doi.org/10.1023/a:1006263818115

Fenton A, Panay N (2016) Estrogen, menopause and joints. Climacteric 19:107-108. https://doi.org/10.3109/13697 137.2016.1151151

Gaspard U et al (2020) A multicenter, randomized study to select the minimum effective dose of estetrol (E4) in postmenopausal women (E4Relief): part 1 Vasomotor symptoms and overall safety. Menopause 27:848-857. https://doi.org/10.1097/GME.00000 00000001561

Giretti MS et al (2014) Effects of estetrol on migration and invasion in T47-D breast cancer cells through the actin cytoskeleton. Front Endocrinol (Lausanne) 5:80. https://doi.org/10.3389/fendo .2014.00080

Hagen AA, Barr M, Diczfalusy E (1965) Metabolism of 17-BetaOestradiol-4-14-C in Early Infancy. Acta Endocrinol (Cph) 49:207-220 
Haque MM, Desai KV (2019) Pathways to endocrine therapy resistance in breast cancer. Front Endocrinol (Lausanne) 10:573. https://doi. org/10.3389/fendo.2019.00573

Holinka CF, Brincat M, Coelingh Bennink HJ (2008) Preventive effect of oral estetrol in a menopausal hot flush model. Climacteric 11(Suppl 1):15-21. https://doi.org/10.1080/13697130701822807

Howie LJ et al (2019) Outcomes of older women with hormone receptor-positive, human epidermal growth factor receptor-negative metastatic breast cancer treated with a CDK4/6 inhibitor and an aromatase inhibitor: an fda pooled analysis. J Clin Oncol 37:3475-3483. https://doi.org/10.1200/JCO.18.02217

Ingle JN et al (1981) Randomized clinical trial of diethylstilbestrol versus tamoxifen in postmenopausal women with advanced breast cancer. N Engl J Med 304:16-21. https://doi.org/10.1056/NEJM1 98101013040104

Janni W et al (2019) Update breast cancer 2019 part 2-implementation of novel diagnostics and therapeutics in advanced breast cancer patients in clinical practice. Geburtshilfe Frauenheilkd 79:268-280. https://doi.org/10.1055/a-0842-6661

Jordan VC (2015) The new biology of estrogen-induced apoptosis applied to treat and prevent breast cancer. Endocr Relat Cancer 22:R1-31. https://doi.org/10.1530/ERC-14-0448

Kluft C et al (2017) Reduced haemostatic effects with drospirenonebased oral contraceptives containing estetrol versus ethinyl estradiol. Contraception 95:140-147

Kwan ML et al (2017) Patterns and reasons for switching classes of hormonal therapy among women with early-stage breast cancer. Cancer Causes Control 28:557-562. https://doi.org/10.1007/s1055 2-017-0888-9

Lasheen S, Shohdy KS, Kassem L, Abdel-Rahman O (2017) Fatigue, alopecia and stomatitis among patients with breast cancer receiving cyclin-dependent kinase 4 and 6 inhibitors: a systematic review and meta-analysis. Expert Rev Anticancer Ther 17:851856. https://doi.org/10.1080/14737140.2017.1355242

Makubate B, Donnan PT, Dewar JA, Thompson AM, McCowan C (2013) Cohort study of adherence to adjuvant endocrine therapy, breast cancer recurrence and mortality. Br J Cancer 108:15151524. https://doi.org/10.1038/bjc.2013.116

Mawet M, Maillard C, Klipping C, Zimmerman Y, Foidart JM, Coelingh Bennink HJ (2015) Unique effects on hepatic function, lipid metabolism, bone and growth endocrine parameters of estetrol in combined oral contraceptives. Eur J Contracept Reprod Health Care 20:463-475. https://doi.org/10.3109/13625187.2015.10689 34

Messina C, Cattrini C, Buzzatti G, Cerbone L, Zanardi E, Messina M, Boccardo F (2018) CDK4/6 inhibitors in advanced hormone receptor-positive/HER2-negative breast cancer: a systematic review and meta-analysis of randomized trials. Breast Cancer Res Treat 172:9-21. https://doi.org/10.1007/s10549-018-4901-0

Reinert T, Barrios CH (2017) Overall survival and progression-free survival with endocrine therapy for hormone receptor-positive, HER2-negative advanced breast cancer: review. Ther Adv Med Oncol 9:693-709. https://doi.org/10.1177/1758834017728928

Singer CF et al (2014) Antiestrogenic effects of the fetal estrogen estetrol in women with estrogen-receptor positive early breast cancer. Carcinogenesis 35:2447-2451. https://doi.org/10.1093/carcin/ bgu144

Song RX et al (2001) Effect of long-term estrogen deprivation on apoptotic responses of breast cancer cells to 17beta-estradiol. J Natl Cancer Inst 93:1714-1723. https://doi.org/10.1093/ jnci/93.22.1714

Szostakowska M, Trebinska-Stryjewska A, Grzybowska EA, Fabisiewicz A (2019) Resistance to endocrine therapy in breast cancer: molecular mechanisms and future goals. Breast Cancer Res Treat 173:489-497. https://doi.org/10.1007/s10549-018-5023-4

Visser M, Holinka CF, Coelingh Bennink HJ (2008) First human exposure to exogenous single-dose oral estetrol in early postmenopausal women. Climacteric 11(Suppl 1):31-40. https://doi. org/10.1080/13697130802056511

Visser M, Kloosterboer HJ, Coelingh Bennink HJT (2012) Estetrol prevents and suppresses mammary tumors induced by DMBA in a rat model. Horm Mol Biol Clin Invest 9:95-103

Publisher's Note Springer Nature remains neutral with regard to jurisdictional claims in published maps and institutional affiliations. 